\title{
Intracerebral amyloidoma Imaging findings might support preoperative diagnosis
}

\author{
Antônio José da Rocha', Carlos Jorge da Silva', José Fábio Santos Leopoldino² , Victor Piana de Andrade ${ }^{3}$
}

A 43-year-old woman presented a severe headache, recent right hemiparesia and disphasia. CSF analysis was unremarkable and imaging studies confirmed two expansive lesions on brain hemispheres (Fig 1). Stereotactic biopsy analysis (Fig 2) confirmed cerebral amyloid tumor (amyloidoma). There was no evidence of systemic amyloidosis, neither underlying inflammatory nor neoplastic disorder. Pathogenesis of amyloidoma remains unclear, while it is the rarest presentation of the brain involvement by amyloid proteins ${ }^{1,2}$. Current literature has only a few previously reported cases, which describe adults with seizures, headache, focal motor signs or cognitive decline $^{1,2}$. This diagnosis should be considered in soli- tary or multiple intracerebral white matter masses with little or no mass effect, hyperdense on nonenhanced CT scans ${ }^{1}$. Amyloidoma is characterized on MR images by the coexistence of a radial enhancement after gadolinium $(\mathrm{Gd})$ administration associated with hypointense stripes on $\mathrm{T}^{2}$. This peculiar pattern could support the preoperative diagnosis and prevent unnecessary surgical resection.

\section{REFERENCES}

1. Lee J, Krol G, Rosenblum M. Primary amyloidoma of the brain: CT and MR presentation. AJNR Am J Neuroradiol 1995;16:712-714.

2. Renard D, Campello C, Rigau V, de Champfleur N, Labauge P. Primary brain amyloidoma: long-term follow-up. Arch Neurol 2008;65:979-980.

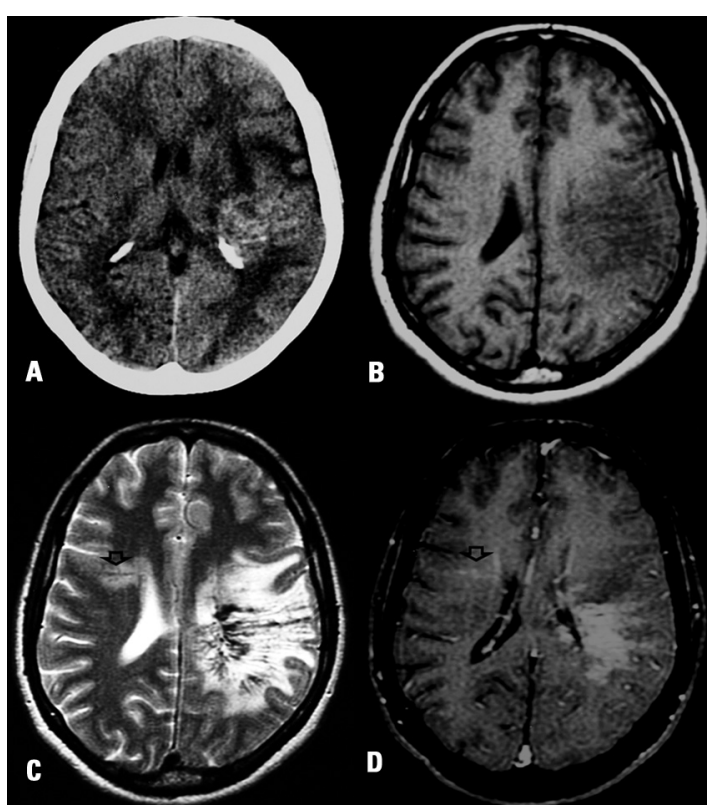

Fig 2. The histological analysis of the left lesion, stained with Congo red and viewed under polarized light demonstrates a typical dichromic blue-green birefringence.
Fig 1. [A] Axial nonenhanced $C T$ image shows a large hyperdense lesion in the left hemisphere. [B] Axial T1-weighted image depicts the lesion with a slight mass effect. [C] Axial T2-weighted image shows hypointense stripes within this periventricular lesion. [D] Axial post-Gd T1 image shows a radial Gd enhancement of this lesion along the Virchow-Robin spaces, with a peripheral extension through parietal subcortical white matter. Note also a smaller lesion in the right hemisphere (arrows in C and D).

\section{AMILOIDOMA INTRACEREBRAL: OS ACHADOS DE IMAGEM PODEM PRESUMIR O DIAGNÓSTICO PRÉ-OPERATÓRIO}

${ }^{1}$ Fleury Medicina e Saúde, Section of Radiology, São Paulo SP, Brazil; ${ }^{2}$ Universidade Federal de Sergipe, Voluntary Professor of Neurology, Aracaju SE, Brazil; ${ }^{31}$ Fleury Medicina e Saúde, Section of Pathology, São Paulo SP, Brazil.

Correspondence: Carlos Jorge da Silva - Centro de Medicina Diagnóstica / Setor de Imagem / Fleury Medicina e Saúde - Rua Cincinato Braga 282 - 01333 -910 São Paulo SP - Brasil. E-mail: carlos.silva@fleury.com.br

Received 12 December 2010. Received in final form 14 December 2010. Accepted 21 December 2010. 